\title{
Pupil changes in persons aged 8 to 79 during text reading - an eye-tracking study
}

\author{
Paweł Kazubowski ${ }^{1}$, Wladysław Błasiak ${ }^{2}$ \\ ${ }^{1}$ Center of Optics, Optometry and Visual Rehabilitation, Pila, Poland, \\ e-mail: pawel.kazubowski@gmail.com \\ ${ }^{2}$ Pawel Wlodkowic University, Plock, Poland, \\ e-mail: wladyslaw.blasiak@gmail.com
}

\section{SUMMARY}

\begin{abstract}
The Eye Tribe eye-tracker was used to capture pupil sizes and fixation times of 40 people aged 8 to 79 years during text reading. The dependence of the number of readable lines on the participants' age was determined. A function describing the dependence of the eye surface area on age was also derived. Visual perception of the maximum number of consecutive lines with decreasing text font size is best for people aged 30-40. For the studied age group, the pupil area decreased with age by approximately $300 \%$. An approximately two-fold increase in average fixation times was recorded.
\end{abstract}

Key words: eye, pupil, reading, age, eye-tracking.

\section{Introduction}

The purpose of this study was to examine pupil changes during text reading in different font sizes. It was aimed to determine the effect of the font size on text reading and text identification, based on readers' age range. The practical goal was to determine the effect of font size on text reading for people of a wide age range.

The diameter of the pupil of the human eye varies from $2 \mathrm{~mm}$ in bright daylight to approximately $8 \mathrm{~mm}$ in the dark. Under twilight vision, the pupil has an average diameter of $6 \mathrm{~mm}$ (Walker et al. 1990). When full illumination in daylight is changed to darkness at the night, the total amount of energy reaching the eye decreases about 16 times. The number of photons falling into the human 
pupil during daylight is unimaginably large: approximately a billion photons fall into the eye in a dimly lit room in one second. During extreme darkness, the human eye reacts to just a few photons falling within 0.1 seconds (Blasiak 2018). The pupil surface area is controlled by two types of muscles. One of them causes constriction of the pupil, and the second causes dilation of the pupil (Gamlin 2002; Kardon 2005).

Many studies have discussed changes in the pupil's rate of reaction with age, and the decrease in its surface area (Duane 1912; Kumnick 1954; Campbell 1957; Kaldecova et al. 1958; Campbell et al. 1966; Hess 1975; Loewenfed I 1979; Kashurirangan et al. 2006; Kowler 2011; Netto et al. 2004). Ageing reduces the effectiveness of the muscles that control the size of the pupil and its response to light intensity. Decades ago, Birren conducted research on a group of 222 people aged 20 to 89 (Birren et al. 1950). The results showed that the pupil size significantly decreased with age. In another study, Watson developed mathematical formulae that described the dependence of the pupil size on various parameters (Watson et al. 2012). Due to the rapid development of visual media, we are exposed to various visual dysfunctions. Thus, improved data statistics and models of changes are required to evaluate the changes in the pupil of the human eye with age.

Pupil dilation is easily induced pharmacologically by applying atropine drops. Similar effects are caused by the consumption of certain plants, such as blueberries. Pupil dilation is also caused by alcohol poisoning and the use of psychoactive substances, such as amphetamines, cocaine, LSD (lysergic acid diethylamide), marijuana, or various types of drugs.

Wide pupils may be associated with the intake of drugs from the group of tropane alkaloids, antihistamines, drugs for Parkinson's disease, and many others. Over-normative enlargement of pupils may also be associated with nervous system diseases or head injuries, such as concussion. According to a study published in the Journal of Autism and Developmental Disorders, autistic children responded to light more slowly and less effectively than people in the control group (Fan et al. 2009; Daluwatte et al. 2013). 
Some studies suggest a relationship between certain parameters of the pupil and intelligence. Tsukahara suggests a relationship between pupil size and individual cognitive ability (Tsukahara et al. 2016). Other studies have concluded that this is questionable (Ackerman et al. 2005; Conway et al. 2003; Harrison et al. 2014; Heitz et al. 2006; Harrison et al. 2014). In our opinion, the findings of these reports are still uncertain and require additional research.

Reduction of the size of the diaphragm in the optical system can reduce the contrast of the image. Older people above the age of 60 require much more lighting to read comfortably than people in their $20 \mathrm{~s}$, due to the reduction in pupil size.

The present study focuses on the changes in the surface area of the pupil during the reading of text and small letters, in 40 people aged 8 to 89 years.

\section{Research method}

The experiment was carried out at the Center for Optics, Optometry and Rehabilitation of the Visual System in Piła, Poland, in 2019 (Blasiak 2019; Kazubowski 2017).

An eye-tracker called Eye Tribe was used for the tests. During the experiment, the Eye Tribe camera was set to track eye movement, passing information to the computer about the diameter of the pupil and fixation time, with a frequency of $60 \mathrm{~Hz}$. The subjects were sitting in front of a monitor, which displayed successive lines of complex strings of words with letters of progressively smaller size. The size of the monitor was 17 inches. The distance from the monitor to the observer was $60 \mathrm{~cm}$. The intensity of light during the experiment was $200 \mathrm{~lx}$, and the light color was $4000 \mathrm{~K}$. Respondents were free to use a computer mouse. The results were compiled using Ogama software. 
The instructions displayed at the top of the screen were as follows: "Read the following sentence carefully. While reading, point the mouse cursor to the words being read." Subjects continued to read words on successive lines up to the point where the font size was impossible to read.

\section{Results}

Figure 1 shows the number of lines read by people aged 8 to 79 . The dotted curve is the best fit for the quadratic function.

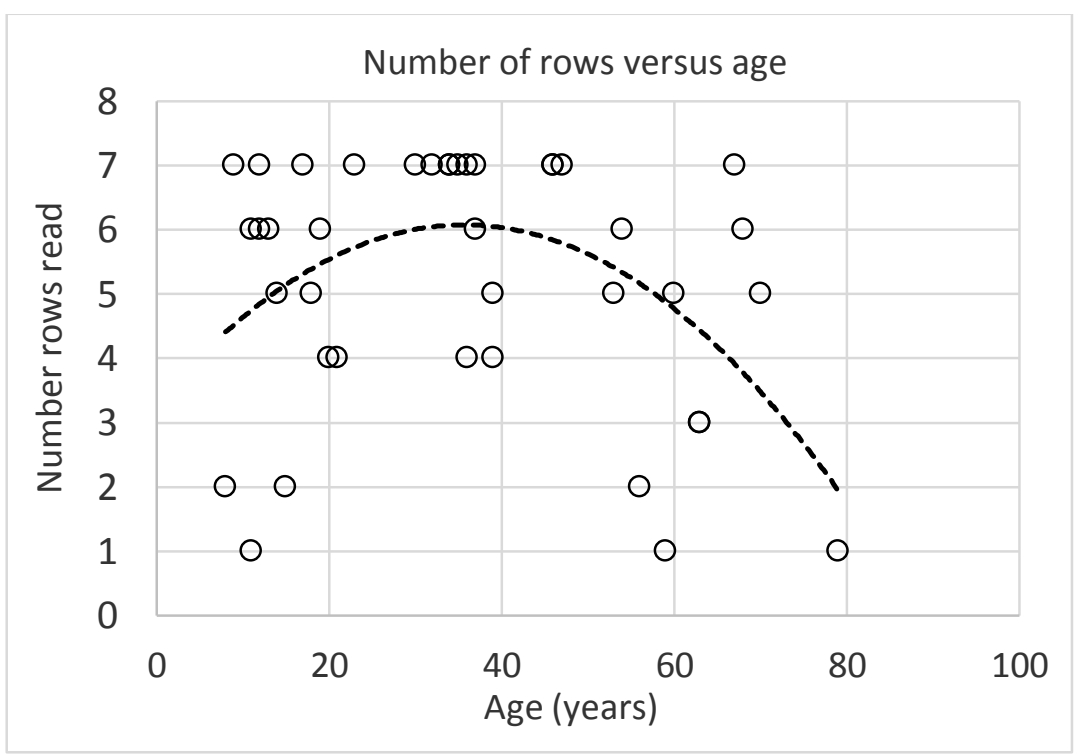

Figure 1. Relationship between the number of lines read and the age of participants

Figure 2 shows the relationship between the eye pupil area and the age of the participants. The mean value of the pupil area was calculated over the entire reading time, that is, for all the lines read (from the largest font to the smallest). For persons aged 8 to 32 years ("Young") a linear function was fitted, and for those between 34 and 87 ("Older") a quadratic function was used. 


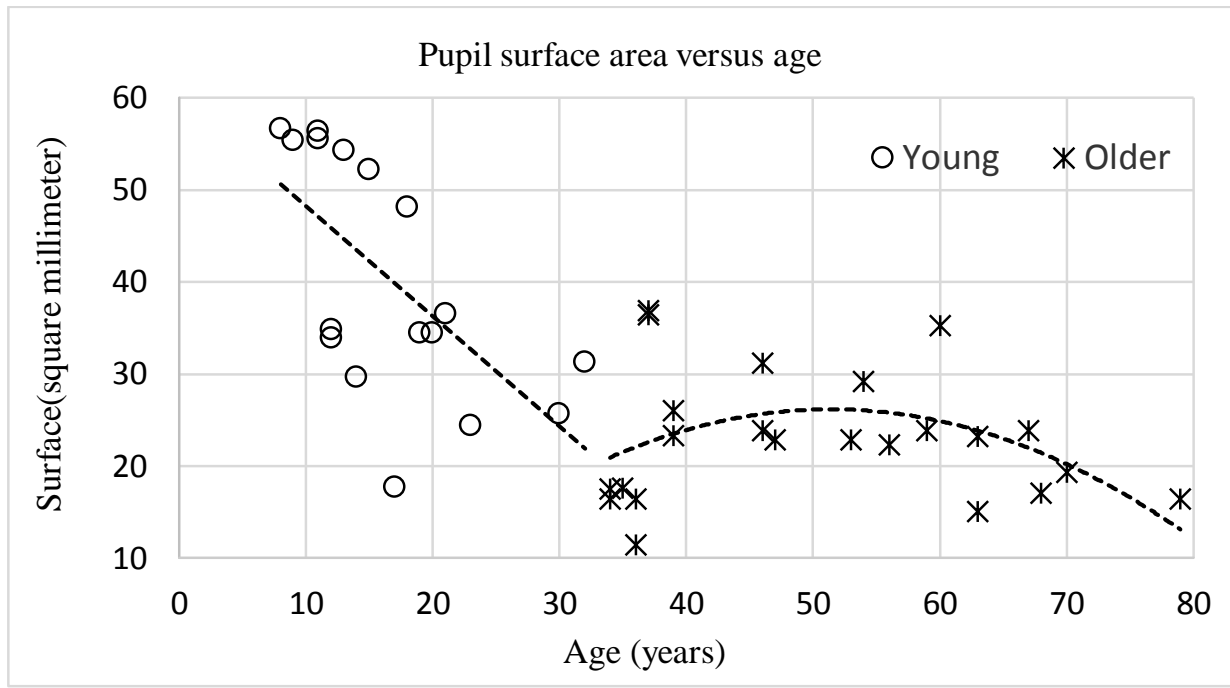

Figure 2. Dependence of pupil area on the age of participants

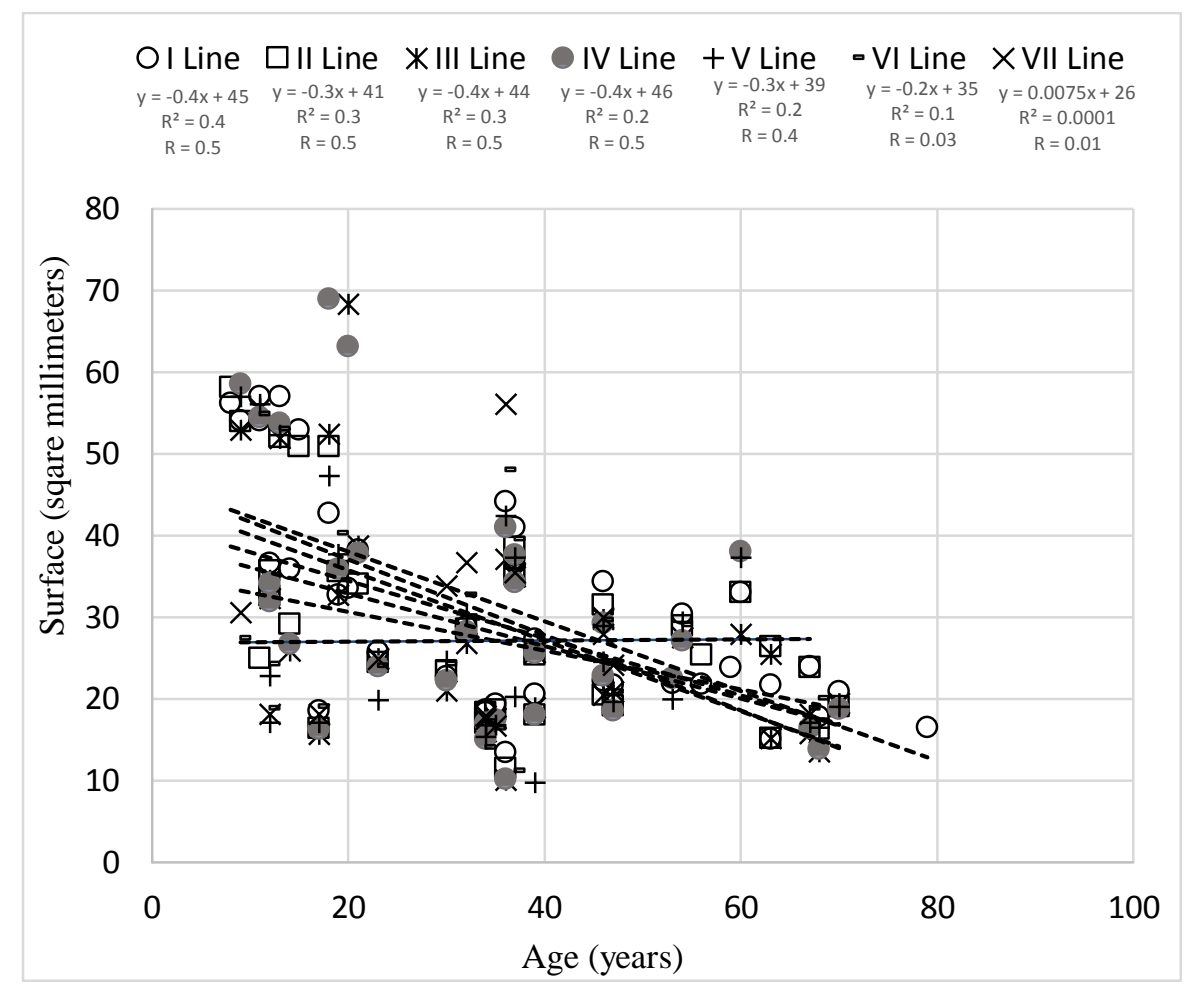

Figure 3. Dependence of the pupil area on the age of participants for words of various font sizes (largest for the 1st row and smallest for the 7th row) 
Figure 3 shows the relationship between the area of the pupil and the age of participants for various font sizes, from the largest (row I) to the smallest (row VII).

The experiments also determined fixation times for all participants while reading the text. No significant correlation was noted between mean fixation time and age. However, significantly higher values of fixation time were recorded as smaller text fonts were read. Figure 4 presents the values of mean fixation time (in ms) for all participants for successive lines.

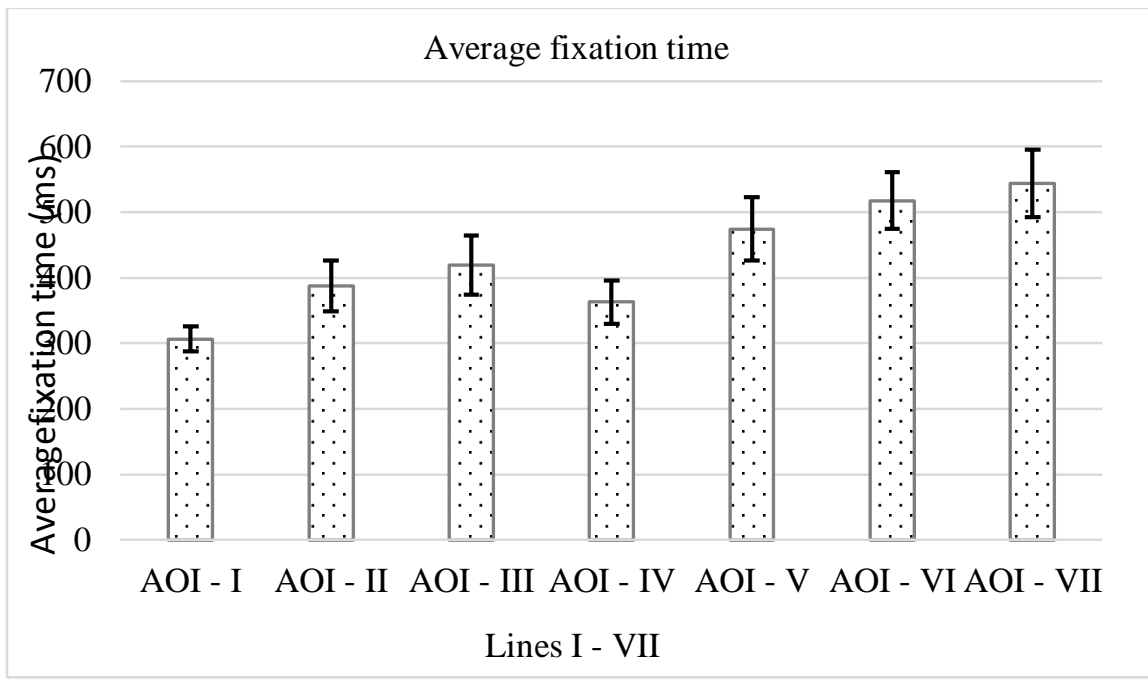

Figure 4. Dependence of average values of fixation time on the font size (from largest to smallest)

\section{Discussion}

The number of lines read decreased with an increase in the age of participants. Figure 1 shows the best fit with a quadratic function. The maximum number of readable lines with decreasing font size is found in the age range from 30 to 40 years (peaking at 35). An appropriate fit of the quadratic function was as follows: $n=0.002 t^{2}+0.02 t+3.3$ (where $n$ is the number of lines read, and $t$ is age in years). A linear approximation was $n=-0.02 t+5.8$. 
Pearson's correlation coefficient was 0.2 , which indicates relatively large individual differences in vision quality for people of similar age.

The pupil surface area significantly decreases in the age range from 8 to 35 years ("Young"; Fig. 2). An appropriate fit in this interval is given by a linear function: $y=-1.2 x+60$, where $y$ is the pupil area (in $\mathrm{mm}^{2}$ ) and $x$ is the subject's age (in years). The Pearson coefficient for this fit is $\mathrm{R}=0.6$. The pupil size does not change significantly in the older age range, from 35 to 87 years. Figure 2 shows the fit with a quadratic function. An appropriate linear fit is $y=0.05 x+25$, and the Pearson's coefficient is only 0.1 . For the studied age group, the pupil area decreased by approximately 3 times.

Figure 3 shows the dependence of the pupil area on the subjects' age for different font sizes. For larger fonts (row I) we observe a slight decrease in the size of the pupillary opening with age $(\mathrm{R}=0.67)$. As the font size decreases (in the order from I to VII), the dependence becomes weaker.

The increase in fixation time shown in Figure 4 reflects the increased effort made by the brain due to eye strain resulting from the decreasing fonts.

\section{Conclusions}

The results confirm the findings of other authors that the pupil area during text reading decreases with age (Hess 1975; Kashurirangan et al. 2006). These authors show that the decrease in pupil area with age, commonly regarded as a medical canon, is significant only for relatively young people. The dependence of the pupil area $y\left(\right.$ in $\mathrm{mm}^{2}$ ) on age $x$ (in years) can be approximated by the decreasing linear function $y=-1.2 x+60$. For people over 35 years of age, the mean pupil area does not change significantly.

\section{REFERENCES}

Ackerman P.L., Beier M.E., Boyle M.O. (2005): Working memory and intelligence: The same or different constructs Psychological Bulletin, 
131(1), 30-60. http://dx.doi.org/10.1037/0033-2909.131.1.30

Birren J., Casperson R., Botwinick J. (1950): Age Changes in Pupil Size. Journal of Gerontology (5): 216-221.

Blasiak W. (2018): Słońce i my, Światło w dziejach człowieka, sztuce, religii, nauce i technice. Wydawnictwo Ruthenus: 61-72.

Blasiak W, Kazubowska K., Kazubowski P. (2019): Age-Related Differences in Visual Perception Between People Aged from 7 to 83: an Eye-tracking Study, Journal of Cognitive Enhancement.

Campbell F. (1957): The depth of field of the human eye, Optica Acta 4: 157-164.

Campbell F., Gubisch W. (1966): Optical quality of the human eye. The Journal of Physiology 186: 558-578.

Conway A.R.A., Kane M.J., Engle R.W. (2003): Working memory capacity and its relation to general intelligence. Trends in Cognitive Sciences 7(12): 547-552. http://dx.doi.org/10.1016/j.tics.2003.10.005

Daluwatte C., Miles J., Christ S., Beversdorf D., Takahashi T., Yao G. (2013): Atypical pupillary light reflex and heart rate variability in children with autism spectrum disorder. Journal of Autism 8: 1910-1925.

Duane A. (1912): Normal values of the accommodation at all ages. Journal of the American Medical Association: 1010-1013.

Fan X., Miles J., Takahashi N., Yogo E. (2009): Abnormal transient pupillary light reflex in individuals with autism spectrum disorders, $\mathrm{J}$ Autism Dev Disord., 39: 1499-508.

Gamlin P. (2002): Neural mechanisms for the control of vergence eye movements. Annals of the New York Academy of Sciences 956: 264-272.

Harrison T.L., Shipstead Z., Engle R.W. (2014): Why is working memory capacity related to matrix reasoning tasks? Memory \& Cognition, 1-8. http://dx. doi.org/10.3758/s13421-014-0473-3.

Hess E. (1975): The role of pupil size in communication, Scientific American 235: $110-119$.

Heitz R.P., Redick T.S., Hambrick D.Z., Kane M.J., Conway A.R.A., Engle R.W (2006): Working memory, executive function, and general fluid intelligence are not the same. Behavioral and Brain Sciences, 29(02): 135-136.

Kaldecova V., Peleska M., Vasko A. (1958): Dependence of Age of the Diameter of the Pipil in the Dark. Nature 182: 1520-1528.

Kardon R. (2005): Anatomy and physiology of the autonomic nervous system. Lippincott Williams \& Wilkins: 649-714. 
Kashurirangan S., Glasser A. (2006): Age related changes in the characteristics of the near pupil response. Vision Research 46: 1393-1403.

Kazubowski P. (2017): The eyetracking research of oculometric parameters in the process of solving physics problems. Dissertation, Polish Academy of Science.

Kumnick L. (1954): Pupillary Psychosensory Restitution and Aging. Journal of the Optical Society of America, (44): 735-740.

Loewenfed I. (1979): Pupillary changes related to age, In: Thompson H.S., Daroff R., Frisen L., Glaser J.S., Sanders M.D. (ed.). Topics in NeuroOphthalmology, Baltimore, Williams \&Wilkins: 124-50.

Netto M., Ambrosio R., Jr., S.E. Wilson J. (2004): Pupil size in refractive surgery candidates, Journal of Refractive Surgery 20: 337-342.

Tsukahara J., Harrison T., Engle R. (2016): The relationship between baseline pupil size and intelligence. Cognitive Psychology 91: 109-123.

Walker H., Hall W. (1990): Clinical Methods: The History, Physical, and Laboratory Examinations. Boston, Butterworths.

Walker H., Hall W., Hurst J. (1990): Clinical Methods: The History, Physical, and Laboratory Examinations, 3rd edition, Chapter 58.

Watson A., Yellott J. (2012): A unified formula for light-adapted pupil size, Journal of Vision 12: 1-16. 